for those with lower community functioning. Participation in competitive employment was also promoted by shorter initial working hours, higher education and disclosure of disabilities. Future prospective, longitudinal research with larger samples, in stratified baseline conditions, is needed.

\section{EVALUATION OF SUBJECTIVE SCALES FOR MEASURING MENTAL WORKLOAD: LITERATURE REVIEW}

${ }^{1}$ FF Alpert*, 'DS Harada, ${ }^{2}$ FR Bonnet, ${ }^{3} \mathrm{KJP}$ Campos, ${ }^{3} \mathrm{MJF}$ Gimenes, ${ }^{4}$ EC Sá, ${ }^{5}$ DR Muñoz. ${ }^{1}$ Occupational and Environmental Medicine (OEM) Residents, University of São Paulo (USP), São Paulo, Brazil; ${ }^{2}$ Preceptor, OEM Residency Program, USP, São Paulo, Brazil; ${ }^{3}$ Associate Professor, OEM Residency Program, USP, São Paulo, Brazil; ${ }^{4}$ Supervisor, OEM Residency Program, USP, São Paulo, Brazil; ${ }^{5}$ Head Professor, OEM Residency Program, USP, São Paulo, Brazil

\subsection{6/oemed-2018-ICOHabstracts.1727}

Introduction Workers' mental health should be valued since the causes of work abandonment due to problems related to mental health already occupy the first position in the statistics in some countries. Knowledge about the means of measuring the mental load in the work environment can help the occupational health team to identify causes of absence, propose ways of prevention, seeking a better adaptation of the work cycle to the worker. The comprehension of the measurement methods available in the literature also helps to guide the choice of the most appropriate scale according to the type of demand to be applied.

Methods Literature review about the forms of evaluation of mental workload, carried out between June and November of 2016, using the following descriptors combined: 'occupational mental load', 'Mental work load', and 'NASA-TLX' at SciELO, Lilacs and Medline databases.

Result A total of 34 articles were selected, of which $80 \%$ used the NASA-TLX scale as a method of analysis or as a comparison for validation of new scales.

Discussion The mental workload scales should be selected according to what is prioritised in the research results. In addition, variability may occur in the application of the same scale with different populations; which corroborates with the definition that the mental load has factors that are specific to the individual and his sociocultural environment. Thus, external and personal factors may interfere in different ways in the assessment of mental load expenditures according to the task.

\section{MENTAL DISORDERS AMONG URBAN BUS DRIVERS}

${ }^{1}$ FF Alpert ${ }^{*},{ }^{1} D S$ Harada, ${ }^{2}$ FR Bonnet, ${ }^{3} \mathrm{MV}$ Braga, ${ }^{3} \mathrm{CM}$ Medeiros, ${ }^{4}$ EC Sá, ${ }^{5} \mathrm{DR}$ Muñoz. ${ }^{1}$ Occupational and Environmental Medicine (OEM) Residents, University of São Paulo (USP), São Paulo, Brazil; ${ }^{2}$ Preceptor, OEM Residency Program, USP, São Paulo, Brazil; ${ }^{3}$ Associate Professor, OEM Residency Program, USP, São Paulo, Brazil; ${ }^{4}$ Supervisor, OEM Residency Program, USP, São Paulo, Brazil; ${ }^{5}$ Head Professor, OEM Residency Program, USP, São Paulo, Brazil

\subsection{6/oemed-2018-ICOHabstracts. 1728}

Introduction The urban bus driver work has several implications, being of great importance the fact that it develops in a public environment. The traffic isn't a defined workspace, being an environment of constant shift and, for that reason, differently from most workers, the bus driver practice his labour outside of the territorially demarcated business environment. This situation exposes this profession to the interference of a diversity of risk factors that many times are out of the scope of its competence. The aim of this study was to identify the most prevalent risk factors and prevention strategies to avoid the illness among the urban bus drivers, in the period of 2006-2016.

Methods A literature survey involving the subject of mental health and the urban bus drivers was made by a direct consultation of scientific articles published in Scielo, Lilacs and Medline database, published from 2006 to 2016.

Result After peer-reading and selection of abstracts according to the parameters described above, fourteen articles were selected and analysed.

Discussion The labour influences the physiological and mental state of the driver, which can lead to irritability, insomnia and attention disturbances. The act of driving is exhausting and its performance is related specially to environment factors of the labour working space and the individual form of coping. Therefore, labour and health conditions of the urban collective bus driver may be considered as psychic and organic pathologies sources. The organisational aspect of labour exerts a great influence over the psychic disorders in this group of professionals, such as the relationship with bosses and colleagues, stability and professional bond and work requirement in relation to the conditions offered. External factors such as road conditions, intense traffic, transit regulations and violence, also exerts a strong influence over the psychosocial health of the urban bus driver.

\section{IS THERE A RELATIONSHIP BETWEEN LEADERSHIP AND PRESENTEEISM?}

${ }^{1} \mathrm{~N}$ Amler*, ${ }^{2} \mathrm{M}$ Hasenbrinck, 'W Fischmann, ${ }^{1} \mathrm{~A}$ Voss, ${ }^{1} \mathrm{E}$ Wischlitzki, ${ }^{2} \mathrm{O}$ Schöffski, ${ }^{1} \mathrm{H}$ Drexler. ${ }^{1}$ Institute of Occupational, Social and Environmental Medicine, University Erlangen-Nuremberg, Erlangen, Germany; ${ }^{2}$ Chair of Health Management, University Erlangen-Nuremberg, Nuremberg, Germany

\subsection{6/oemed-2018-ICOHabstracts. 1729}

Introduction According to the literature presenteeism (defined as people turning up at work despite illness) is closely related to work related factors such as high job demands, time pressure or difficulties in staff replacement. On the other hand, there is growing evidence that managers and supervisors have a huge impact on employees' health and well-being. We have been wondering if leadership also has an effect on employees' behaviour in case of illness.

Methods PubMed, Business Source Complete and PsycINFO were searched for relevant literature. Internet search and scanning reference lists complemented our search. Two authors independently reviewed titles, assessed articles' eligibility and extracted relevant data. Papers examining presenteeism in the context of management or leadership were included. Articles in languages other than English or German were excluded from further research.

Results In total 418 studies were identified. 27 met the inclusion criteria. The majority of studies addressed the role of managers with regard to the disclosure of diseases, within return-to-work discussions or in integration management. Others analysed the impact of different leadership styles on presenteeism in general. Studies suggest that the leaders' own behaviours in case of illness as well as their attitudes towards 